\title{
The dynamics of Family Language Policy in a trilingual family: A longitudinal case study
}

\author{
Emilia WĄSIKIEWICZ-FIRLEJ, \\ Uniwersytet im. Adama Mickiewicza w Poznaniu/Adam Mickiewicz University \\ in Poznań \\ E-mail: emiliawf@amu.edu.pl,
}

\author{
Hadrian LANKIEWICZ \\ Uniwersytet Gdański/ University of Gdańsk \\ E-mail: hadrianlank@interia.pl,
}

\begin{abstract}
Family Language Policy (FLP) is a pioneering yet dynamically thriving interdisciplinary field of study, which successfully integrates language acquisition, multilingual studies, sociolinguistics and ecolinguistics. The present paper reports on the longitudinal case study of a Polish-Japanese family residing in the UK and the development of their family language policy. Through a specific focus on narrative data and observations, obtained in two cycles of research in 2014/15 and 2017, it illustrates the parents' attitudes towards their minority languages (Polish and Japanese, respectively), the majority language (English) and their child's multilingualism. Irrespective of the parents' positive attitudes towards multilingualism and their declared efforts to raise a trilingual child, the original study (E. WąsikiewiczFirlej 2016) showed the dominance of the majority language in the family, and pointed to substantial difficulties in the maintenance of minority languages, which was mostly explicated by the child's agency in shaping FLP. The results of the first stage of the study (2014/15) have been juxtaposed with the data obtained in 2017 in order to verify the parents' declared vs. actual language management, as well as the dynamics of FLP over time. The findings have confirmed the assumed dynamic character of the family's language policy, which is shaped by a range of constantly changing micro and macro factors, contributing to a better understanding of FLP sociolinguistic ecology.
\end{abstract}

Keywords: FLP, language ideologies, language management, multilingualism

\section{Introduction}

Reflecting the burgeoning interest in the field of family language policy (FLP), advanced by K. King/ L. Fogle (2013) and K. King/ L. Fogle/ A. Logan-Terry (2008), the current paper focuses on the process of child language socialization in a multilingual transnational family, which in the light of FLP is to a great extent shaped by parents' language ideologies, and their decisions concerning language and literacy development. This impact has been confirmed in a number of studies (e.g. E. Ochs/ B. Schieffelin 1984, E. Lanza 1997), yet more recent publications also point to the child's agency (e.g. L. Fogle 2012). 
Earlier studies tended to focus on two-parent, middle-class, bilingual families using European languages. The current study, however, addresses a call for more diversified, multilingual family contexts, and it documents the FLP of a Polish-Japanese family residing in the UK. It analyses data from an explorative case study, elicited from cyclical observations and a series of semi-structured interviews with all family members that took place in 2014/2015, as well as the data from the sequel study conducted in 2017. Generally, the original study reported the essential difficulties in maintaining the child's multilingualism, due to the limitations on the use of the minority languages (Japanese and Polish) and the dominant use of English in family interactions. The study also pointed to the child's agency, and concluded with the specification of the parents' plans for FLP management, which involved the support of the child's trilingualism. The sequel study, reported in the current work, aims to revisit these policies and verify their realization by juxtaposing previous declarations with the status quo. The main assumption underlying this study is the ecological embedding of FLP and its dynamic character, which is shaped by and adapted to changing micro and macro factors.

\section{Theoretical underpinnings}

Drawing on the assumption that all speech communities have a language policy or policies (B. Spolsky 2004), the present study focuses on the family as a speech community and examines the concept of FLP. Following J.A. Fishman (1991), E. Lanza (2007), M. Schwartz/ A. Verschik (2013), we posit that the family plays a crucial role in forming the child's linguistic environment, and as such it is critical in language maintenance and preservation. Thus, our research is deeply rooted in Haugenian language ecology which studies "interactions between any given language and its environment" (E. Haugen 1972: 325).

Family Language Policy is a relatively new field of research, integrating language acquisition and language policy, which focuses on the study of relations between language policy and family language choice and use (e.g. B. Spolsky 2004, K. King et al. 2008, M. Schwartz 2008, M. Schwartz 2010). In contrast to psycholinguistic studies centring on child language acquisition, FLP concentrates on the actual language use in the family. From this perspective, child language learning is seen as an outcome of parents' ideologies, as well as their decisions and strategies concerning language learning, along with the broader sociocultural context of a given family (L. Fogle/ K. King 2013: 172). E. Shoamy (2006) holds that the language policies of a given community might be explicit, implicit or both. Explicit policies are expressed in official laws and documents, contrary to implicit policies, which emerge from the actual language practices of a community (ibid.: 50). For this reason, explicit and implicit policies are not always concomitant and they might be substantially discrepant.

According to K. King/ L. Fogle/ A. Logan-Terry (2008: 907), FLP enables researchers to study the processes of language acquisition in a family as well as the processes of language management in a holistic way. Scholars often apply B. Spolsky's model (2004: 5), which embraces three elements of the language policy of a given community, i.e. language practices (language behaviours), language ideology 
and beliefs, and language management. These three elements are interrelated and influence each other, i.e. ideology affects practices and management but, vice versa, practices and management may shape ideology (B. Spolsky 2004: 14).

The first component, language practices, corresponding with D. Hymes's (1967, 1974) "ethnography of speaking", is defined as the more or less conscious lexical, grammatical, phonetic and language choices made by an individual (B. Spolsky, 2004: 9). Numerous studies have shown that parental language practices have a detrimental effect on a bilingual child's language development, pointing both to the quantity and quality of parental input (e.g. S. Döpke 1992, C. Hoffmann 1985, A. de Houwer 2007). In other words, reduced exposure to a minority language is followed by a decrease in the child's minority language use (A. de Houwer 2007). Parents also play a key role in establishing family language policy. On the other hand, recent studies (e.g. S. Caldas/ S. Caron-Caldas 2000, 2002) also emphasise the role of children as members of the speech community in shaping FLP.

The second component, language ideology, stands for the beliefs and ideas about language and language use that are shared by the members of a speech community. They simultaneously arise from and affect practices, and can underlie language management. In contrast to language practices which designate "what people really do", language ideologies and beliefs specify the appropriateness of language use and assign "value and prestige to various aspects of the language varieties" (B. Spolsky 2004: 14). From the perspective of FLP, language ideologies are often defined as specified areas of social and individual cognition, which embrace values, beliefs and attitudes towards language and its use (B. Spolsky 2004, D. Volk/ M. Angelova 2007 W. Wolf$\mathrm{ram} / \mathrm{N}$. Schilling-Estes 2006). They might be analysed both at the macro level, in the national, institutional or global context, as well as the micro level, centring on language attitudes and beliefs within a given family (A. Blackledge/ A. Pavlenko 2002, K. King/ L. Fogle/ A. Logan-Terry 2008). Notably, language ideologies are not solely limited to language but also reflect issues related to social and personal identity (E. Lanza 2007). As V. Moin/ L. Schwartz/ M. Leikin (2013: 101) observe, at the empirical level the focus is switched towards the discursivity and contextuality of attitudes and beliefs (e.g. P. Laihonen 2008, B. Wittenbrink/ N. Schwarz 2007). Based on this assumption, language ideologies are defined as "discourse about language" (P. Laihonen 2008: 669). Accordingly, V. Moin/ L. Schwartz/ M. Leikin (2013) use the term family language ideology in reference to the parents' discourse concerning aims, plans and expectations related to the development of their children's multilingualism. A. de Houwer (1999) contends that parental language ideologies, including, for example, attitudes towards bilingualism, language acquisition or code-mixing, may directly translate into the specific language practices adopted. For example, a belief that codemixing impedes language acquisition and leads to confusion might inhibit the use of this practice both by parents and children. Additionally, language specific beliefs, i.e. ideas concerning the value and status of a given language in society, have an impact on family language use: parents who value their native languages are more prone to endorse them to their children (E. Harding/ P. Riley 1986). 
Finally, for a better understanding of the notion of language management, B. Spolsky (2004: 14) refers to the questions posed by R.L. Cooper (1989: 31) in the context of his research on language spread and change: "who plans what for whom and how". In other words, language management involves an overt effort to transform or manipulate others' language ideologies or practices (X.L. Curd-Christiansen 2009, B. Spolsky 2008). Language management often trespasses, or even stands in opposition to the boundaries delineated by the beliefs, values and language practices shared by a given language community. Simultaneously, language ideologies underlie language management and may be seen as the driving force of concrete attempts to change language use (X.L. Curdt-Christiansen 2009, 2013). At the state - macro - level it concerns the "top-down" formulation of language policies and their further implementation (B. Spolsky 2004: 8). In the micro - family - context, language management efforts are manifested by parents'/ caregivers' attempts to enhance children's language learning, which include the use of their native language in interactions with children, as well as travelling to their home country, arranging encounters with relatives or other speakers of the target language and providing language classes (B. Spolsky 2004: 8). Language management to a large extent overlaps with the strategic use of specific language practices such as corrections or a specific language choice (K. King/ L. Fogle/ A. Logan-Terry 2008: 911).

By and large, FLP research concentrates on the parents' role in preserving "heritage language by modifying children's language development (B. Spolsky 2012: 7). It addresses the question why some children are raised to be bilingual, while others remain monolingual, and how this is related to parents' ideologies and practices which might either promote or discourage the child's use of a given, mostly minority language (X.L. Curdt-Christiansen 2013). Yet, despite being a coalescing field, several strands of research within FLP can be discerned (K. King/ L. Fogle 2006). Initially, FLP research focused on two-parent, middle-class families in which at least two European languages were used (e.g. E. Lanza 1992). Nowadays, research participants also represent families using minority languages, set in a transnational context or residing in diasporas, which are not always qualified as "traditional" and embrace, for example, adoptive or single-parent families (A.S. Canagarajah 2008). Additionally, a growing body of research on the management of family multilingualism can be observed (E. Lanza/ B.E. Svendsen 2007, X.L. Curdt-Christiansen 2009).

Another large research avenue within FLP centres on the perception of the family as a dynamic system and the child's active role in family language socialisation (e.g. T. Okita 2002, J.A. Luykx 2005, E. Lanza 2007, J. Gafaranga 2010, Å. Palviainen/ S. Bond 2013, L. Fogle 2012, L. Fogle/ K. King 2013). E. Lanza (2007: 47) strongly argues for the child's agency not only in terms of language socialisation, but also emphasises its active role in society at large. In her view, the child is not merely formed by society to become a fully-fledged member of it, but essentially contributes to its development. This theme has been thoroughly discussed in the volume edited by M. Schwartz and A. Verschick (2013), which embraces, among others, the paper authored by $\AA$. Palviainen/ S. Bond (2013), indicating that even three-year-old children can actively shape and negotiate FLP. Child agency has been also discussed by 
A. Tuominen (1999), who emphasised children's role in safeguarding the dominance of the majority language (English) at the cost of the minority language. The role of social factors in the selection of a majority language by children from bilingual families has been also identified by S. Caldas/ S. Caron-Caldas (2000, 2002). Moreover, an in-depth case study of a five-member bilingual family using French and English has provided evidence that in puberty children's language preferences are shaped by peers rather than parents (S. Caldas/ S. Caron-Caldas 2000, 2002). These findings corroborate the theory of group socialization put forward by J.R. Harris (1995), which puts a strong emphasis on the superiority of the peer group behavioural system. Research into bilingual families conducted by J.R. Harris (1995) clearly illustrates the shift of ethnic minority families from their minority language towards the majority language, as well as the acquisition of peers', rather than parents' pronunciation by children. Discrepancies between parents and children in the patterns of minority language maintenance have also been discerned in a survey study of 307 migrant children residing in Australia, aged 8-11, carried out by M. Tannebaum (2003).

\section{Research: A longitudinal case study}

The current study is a sequel to the case study of FLP in a transnational trilingual Polish-Japanese family residing in the UK, conducted in 2014-2015 (E. WąsikiewiczFirlej 2016). The study assumes the ecological embedding of FLP and its dynamic nature and aims to:

(1) revisit the FLP of the family under study and monitor its development and management;

(2) define the role of the child in shaping FLP.

A qualitative approach has been applied to the research, which has taken the form of an "intrinsic case study" (R. Stake 2005), designed to obtain "a thick description of a complex social issue embedded within a cultural context" (Z. Dörnyei 2007: 155) and shed some light on the development and management of FLP in a trilingual family. The selection of the case study design might be additionally motivated by the fact that the study investigates a relatively unexplored area and aims to provide some insight into complex longitudinal processes, which would be difficult, or even impossible, to "be adequately researched in any of the other common research methods" (L. van Lier 2005: 195).

Data was collected through semi-structured interviews and observations, which were conducted at the participants' convenience in their home. The procedure of datacollection was two-stage. The first stage embraced the years 2014/15 (13 months) and the second stage in 2017 (October). The interviews with the mother and daughter were conducted in English and the father was interviewed in Polish (his native language) so the transcript of his interviews has been translated into English by the authors. The interviews were audio-recorded and selected extracts transcribed to provide some illustrative exemplification. The study also involved observations (30 hours in 2014/15 and 10 hours in 2017), which aimed to verify the participants' declarations expressed in the interviews with their real language practices in everyday interactions. 
The participants in the study were a three-member family, composed of the father Jan (40), mother Ayame (39) and their eight-year-old daughter Maja (as at $31^{\text {st }}$ October, 2017). The names of the family members are pseudonyms, for the sake of anonymity. Jan, a native speaker of Polish, was born and lived in Poland until the age of 25. After graduating from chemical studies in Poland, he obtained a Japanese government grant for PhD studies in Japan, where he spent the next four years. During this period he met his wife Ayame, who was born in Japan and is a native speaker of Japanese. After graduating from secondary school in Japan, Ayame undertook cultural studies in the US, which she was forced to cease after three years due to personal reasons. Jan having completed his $\mathrm{PhD}$ studies, the couple left Japan and settled in the UK, which was motivated by Jan's career choices. Their only child to date, Maja, was born in the UK in 2009.

\section{Results and discussion}

The analysis of the gathered materials, including audio recordings and notes from observations which were repeatedly read and listened to, first aimed at categorising the data into four major themes related to the integral elements of FLP, i.e. family language profile, language practices, language ideology and language management. Next, other themes that emerged from the study were identified and scrutinised. The discussion of research results will reflect this categorisation and focus on comparing and contrasting the data obtained in two stages of the study in order to verify the assumed ecological embedding of FLP and its dynamic nature.

\subsection{Family language profile}

As far as the family's language profile is concerned, the dominant language in their private interactions is English, which is the parents' second and the daughter's native language. The level of the parents' English might be evaluated as advanced/near native. Jan competently communicates in English in all contexts, including professional and academic ones, yet his accent is far from native. He declares having intermediate level Japanese, but his use of this language is limited to rare contact with his wife's relatives once or twice a year. Ayame's knowledge of Polish is limited to several dozen words or phrases, used by her to communicate with her mother-in-law. Despite her husband's and his relatives' encouragement, Ayame has not studied Polish systematically. The parents consciously avoid code-mixing in whole-family interactions in order to avoid exclusion of any family member. English also remains their dominant language in the social-institutional context and in father-daughter communication. Ayame seems to be particularly sensitive about any potential exclusion and perceives the use of English as integrating, both in the private and social contexts. Yet part of the mother-daughter interaction is conducted in Japanese. In most cases, however, where Ayame speaks to her daughter in Japanese, the girl mostly replies to her in English. Maja's contact with her extended family is scarce and the girl communicates with her Polish relatives mostly in English, but uses Japanese when staying in Japan (usually four/ five weeks every two years). The only person she communicates 
with in Polish is her grandmother. The diagram below presents the child's pattern of language use.

\begin{tabular}{|l|l|}
\hline \multicolumn{1}{|c|}{ Type of interaction } & \multicolumn{1}{c|}{ Language(s) used } \\
\hline WHOLE FAMILY INTERACTION & English \\
\hline FATHER - MOTHER & English \\
\hline MOTHER - DAUGHTER & Japanese/ English \\
\hline DAUGHTER - MOTHER & English/ Japanese \\
\hline FATHER - DAUGHTER & English \\
\hline SOCIAL/ INSTITUTIONAL CONTEXT & English \\
\hline EXTENDED FAMILY & English, Japanese, Polish (seldom) \\
\hline
\end{tabular}

Table 1. Patterns of language use in the family under study.

Mapping the patterns of language use shows that despite the parents' declarations to have three languages and cultures in their family, English as the majority language clearly dominates in all types of in- and out-of-home interactions. The whole family life revolves around the child, her school, extracurricular classes and social contacts with English-speaking peers. The girl is practically completely immersed in the English language, British culture and her local, English-speaking community. Except for the positive symbolic and cultural values ascribed to English, the parents also recognised the instrumental or economic value of native English as a key to their daughter's educational and future professional success, which is in line with P. Bourdieu's (1991) concept of the cultural capital associated with language proficiency and its potential relation to socio-economic status and power (see also H. Lankiewicz/ E. WąsikiewiczFirlej in press). Japanese has the status of the second language, used occasionally in mother-daughter interaction and rare (usually bi-annual) contacts with Japanese relatives residing in Japan. Polish is the least frequently used language in the family, since Jan has practically ceased to communicate with his daughter in his mother tongue and its use is limited to occasional contacts with Maja's Polish relatives residing permanently in Poland. Thus, in this particular case, minority language loss might be explained by the loss of "natural intergenerational transmission" (B. Spolsky 2012: 2).

The dominance of English in the family under study might also be accounted for by a range of external factors. First of all, outside the home, the family is immersed in a monolingual environment where English has the status of majority language. Additionally, all family members have reported a lack of institutional support for minority languages, either in the workplace or school. Children are by no means encouraged to use minority languages, or offered any help or language assistance; quite the contrary, they feel pressure to conform to the majority language. As far as an informal social network is concerned, the family is not supported by any minority language 
community (neither Polish nor Japanese). Altogether, being detached from their compatriots, the parents have decided to assimilate with their local community for the sake of their daughter's "emotional and social well-being" (Extract 1, Jan 2017). The family does in fact feel isolated and lacks the support of their relatives or minority communities, which makes all family members conform to the majority language and culture to satisfy their sense of belonging. The father has summarised the family's situation metaphorically by saying that "our family is like a tiny island in the middle of the ocean... so there's no point fighting it... we just need to acknowledge it and adapt to the circumstances" (Extract 2, Jan 2017).

\subsection{Language practices in 2015 vs. 2017: A verification}

The following section aims to compare and contrast the language practices in the family in 2015 and 2017, especially in the light of the declarations made in 2015. At that time, both parents were concerned with their daughter's reluctance to communicate either in Polish or Japanese, which is illustrated by the examples below.

Extract 3 (2015)

Ayame: Maja used to be fluent in Japanese. Now she often speaks back to me in English. She tends to forget more and more words.

Extract 4 (2015)

Jan: I sometimes read her some stories in Polish but she always wants me to translate them into English. (...) I'm too lazy and she is too stubborn.

After participation in the 2015 study, the parents seemed determined to change the situation and make more effort to communicate with Maja in their native languages. Ayame did indeed start to provide regular, daily, instruction of Japanese, based on a series of handbooks published by the Japanese Ministry of Education, as well as more frequent informal interaction in Japanese. As a result, since 2015 Maja's competence in written and spoken Japanese has significantly improved. Unfortunately, such satisfactory results cannot be mirrored in the case of Polish, since the girl's proficiency in her father's native language has not developed. In fact, some regressive trends have been noted. Maja's attitude to the use of Polish in 2015 and 2017 might be exemplified by the following extracts:

Extract 5 (2015)

Jan: Maja, chodź poczytamy. [Maja, let's read.]

Maja: I don't want you to read me a Polish book!

Jan: Dlaczego? [Why?]

Maja: I don't like it.

Jan: Dobrze, poczytamy inną. [OK, we can read another one.]

Maja: No! Not in Polish!

Jan: Dlaczego nie? [Why not?]

Maja: Polish is too difficult. I don't like it. 


\section{Extract 7 (2017)}

Jan: Maja, let's read this book you got from aunt Ola.

Maja: I've already done it.

Jan: I know. But we can read in Polish.

Maja: What for? [emphasis added]

As illustrated in Extract 5, back in 2015 Maja did not seem very motivated to use Polish, considered by her as difficult. Yet, her father took some effort to speak to her in Polish and encouraged her to read with him. The girl could perfectly understand her father speaking his native language but persistently refused to use it and responded to him in English. Two years later, in a similar situation Jan does not even make any attempt to interact with his daughter in Polish. He even uses English to read a bilingual (Polish-English) book presented to Maja by her Polish aunt. Having read it in English, the girl cannot see any point in reading it again in Polish with her father. She seems really confused and her father withdraws. Additionally, both in the first and second cycle of interviews, Maja repeatedly refers to her own "Englishness" and treats her parents' native languages as "theirs" not "hers".

\subsection{Language ideologies: 2015 vs. 2017}

A comparison of the results of two cycles of the study (2015 vs. 2017) has clearly showed that the parents' general beliefs of and attitudes towards multilingualism have remained overwhelmingly positive, as exemplified by the extracts below.

\section{Extract 8 (2015)}

Jan: It always has a positive impact on the child's brain and life in general. Bilingual children get better results at school, achieve more in life...

Extract 9 (2017)

Ayame: It is really an asset when you know a few languages...

In 2015, Jan pointed to the discrepancy between his own beliefs, qualified as lay theories in the previous study (E. Wąsikiewicz-Firlej 2016), concerning the process of raising a bi(multi)lingual child, which, contrary to his expectations, had turned out to be challenging.

\section{Extract 10 (2015)}

Jan: I didn't realise that bringing up a bilingual or multilingual child would be so difficult. We thought that you only need to talk to your child in your native language and it would automatically become bi or trilingual. I didn't take into account any resistance on the part of the child. I thought it would be more natural... more effortless. So far English is the only language our daughter has acquired without our significant contribution.

At that time, Jan believed that his use of Polish would exclude Ayame from family interactions and hamper mutual understanding. In other words, the father formulated a lay theory which assumed a potentially negative impact of his use of Polish when 
interacting with his daughter on family relationships, deciding to sacrifice his daughter's bilingualism.

\section{Extract 11 (2015)}

Jan: I mostly use English to communicate with my daughter. My priority is building a positive relationship with Maja, even at the cost of her bilingualism. (...) I work long hours so I highly value spending quality time with her. I do not fancy playing the role of her Polish teacher. (...) Polish impedes our understanding (...) and excludes Ayame.

The above extract points to a certain conflict between the declared general beliefs about multilingualism and specific language beliefs concerning the dominant role of the majority language. After two years, Jan admittedly came to terms with his perceived failure in developing his daughter's competence in Polish and elaborated his lay theory concerning the centrality of English and marginalizing his mother tongue. In his view, "English is more important than some minority languages" (Jan, Extract 12: 2017). Furthermore, Jan perceives speaking English with a foreign accent as a handicap and considers his daughter's native English as a huge advantage, which safeguards her "adequate" position in the British society:

\section{Extract 13 (2017)}

Jan: Native English will make her belong here. (...) with a foreign accent you're always looked down on. (...) I think it is easier for Maja to consider herself British.

A foreign accent is seen by Jan as a serious obstacle, a kind of a glass ceiling, hindering professional development and chances for promotion to higher positions. In Jan's opinion, even the acquisition of British citizenship does not guarantee automatic acceptance and assimilation with the natives, which is illustrated in the following extract:

Extract 14 (2017)

Jan: I've got a feeling that I'll never be one of them... despite my education... my fluency in English (...) I open my mouth and I'm automatically considered an East-European no matter what...

A similar stance is adopted by Ayame who believes that "[s]ince our [the parents'] first language is not English, it is very important for our daughter to learn proper English at school" (Ayame, Extract 15: 2015). Thus, it might be concluded that both parents marginalise themselves as speakers of English and cultivate the myth of the native speaker.

The new ideology that has emerged from the 2017 study might be formulated as "language is a commodity". Ayame also emphasises the role of "proper English" in the British educational context. She strongly believes that it is particularly advantageous in the highly competitive process of applying to top British universities. Additionally, in the 2017 study, the parents also pointed to the market value of native English, safeguarding their daughter's future employability in the globalizing world. In 
this context, they also appreciate the instrumental value of Japanese as a foreign language, seen as an additional asset facilitating university placement and future professional career.

Furthermore, in the 2017 study, Ayame takes a firm stand by formulating a policy concerning the use of language in public places: "In public places we only speak English. We want to belong here" (Ayame, Extract 16: 2017). This decision is accounted for by both parents on the grounds of the current socio-political situation in the UK and the alleged rise of anti-migrant attitudes. They also express their concern related to Brexit and their future status in the British Isles and the EU. This supports X.L. Curdt-Christiansen's (2009) view that both micro and macro level factors influence parental language ideology.

\subsection{FLP management: 2015 vs. 2017}

The dominant theme emerging from the data collected in 2015 was the parents' sense of deep disappointment and failure concerning their child's multiligualism, exemplified by the following extract:

Extract 17 (2015)

Ayame: It sometimes makes me sad that we can't communicate with our own daughter with our own languages (...). We are both a little bit sad that she doesn't speak Polish or Japanese well...

The father shared his reflections on the current developments and attempted to explain the family language dynamics by means of self-formulated lay theories, based on the assumption that his daughter's reluctant use of a heritage language is motivated by her need of belonging and being integrated with peers (see Extract 18 below).

Extract 18 (2015)

Jan: We really, really wanted her to be trilingual... I can't understand... it seems to me that... it's my theory... that she doesn't want to be different. She wants to belong here...

As far as the declared language management is concerned, in 2015 the parents verbalised their need for change and willingness to act, which involved the redefinition of FLP goals and specification of strategies to attain them. First of all, the mother endeavored to provide systematic Japanese language instruction. The parents were also considering their child's participation in Polish classes offered by a nearby weekend Polish school.

The major change in the findings in 2017 compared to 2015 is the acceptance of the status quo, exemplified by the extracts below:

Extract 19 (2017)

Jan: I'm somewhat satisfied (...). I wish she were trilingual but she isn't and I'm not going to make a lot of fuss about it. (...) I didn't realize it requires so much effort. (...) If I were to choose: Saturday Polish school or music school, the choice is obvious to me... 


\section{Extract 20 (2017)}

Ayame: I've been teaching her Japanese for a year now. We have regular classes... try to have them every day. We are using a course book from Japan... (...) She's making some progress but her accent is English. It's really weird. She used to sound Japanese when she was three...

In sum, the whole family seems to have assimilated with their host country and local community, and the majority language (English) has become the major means of communication. Both parents have identified the instrumental value of Japanese as a second language as an asset in academic and professional milieus and, accordingly, the mother provides systematic instruction of her heritage language. The father's heritage language, Polish, is hardly ever used. The parents have completely given up the idea of sending Maja to a nearby Polish weekend school, mainly due to time limitations and a tight family agenda. Additionally, Jan expressed certain reservations concerning the authenticity of the school in terms of its relevance to Polish culture, as well as its value orientation, deemed by him as traditional, national and Catholic. In his opinion, the school's community cherished a specific, rather obsolete image of Poland, detached from reality. Ultimately, Jan has come to the conclusions that this particular mindset did not resonate with the value system he holds and wants to foster in his family.

\section{Conclusions}

This paper has presented the development of FLP in a multilingual Polish-Japanese family residing in the UK. The major findings of the longitudinal study have been juxtaposed in Table 2, which clearly illustrates the dynamics of FLP over the years.

\begin{tabular}{|l|l|l|l|}
\hline \multicolumn{1}{|c|}{ FLP } & Before the child's birth & \multicolumn{1}{|c|}{2015} & \multicolumn{1}{|c|}{2017} \\
\hline $\begin{array}{l}\text { Language } \\
\text { practices }\end{array}$ & \multirow{2}{*}{ OPOL } & $\begin{array}{l}\text { code switching and } \\
\text { mixing }\end{array}$ & $\begin{array}{l}\text { unchanged; idiosyncra- } \\
\text { sies }\end{array}$ \\
\cline { 3 - 4 } & & $\begin{array}{l}\text { dominance of the ma- } \\
\text { jority language (Eng- } \\
\text { lish) }\end{array}$ & strengthened \\
\cline { 3 - 4 } & & $\begin{array}{l}\text { father-child commu- } \\
\text { nication: almost ex- } \\
\text { clusively English }\end{array}$ & unchanged \\
\cline { 3 - 4 } & & $\begin{array}{l}\text { mother-child commu- } \\
\text { nication: mostly Eng- } \\
\text { lish, partly Japanese }\end{array}$ & unchanged \\
\hline
\end{tabular}




\begin{tabular}{|l|l|l|l|}
\hline $\begin{array}{l}\text { Language } \\
\text { ideologies }\end{array}$ & $\begin{array}{l}\text { positive attitude towards } \\
\text { multilingualism per- } \\
\text { ceived as an advantage, a } \\
\text { "gift" stimulating intel- } \\
\text { lectual development }\end{array}$ & unchanged & $\begin{array}{l}\text { unchanged; additionally } \\
\text { strengthened by the par- } \\
\text { ents' recent, more in- } \\
\text { formed interest in multi- } \\
\text { lingualism }\end{array}$ \\
\hline $\begin{array}{l}\text { Language } \\
\text { manage- } \\
\text { ment }\end{array}$ & trilingual education & $\begin{array}{l}\text { monolingual educa- } \\
\text { tion }\end{array}$ & unchanged \\
\cline { 2 - 4 } & British primary school & $\begin{array}{l}\text { British primary } \\
\text { school }\end{array}$ & unchanged \\
\cline { 2 - 4 } & $\begin{array}{l}\text { systematic Japanese lan- } \\
\text { guage instruction pro- } \\
\text { vided by mother }\end{array}$ & $\begin{array}{l}\text { systematic Japanese } \\
\text { language instruction } \\
\text { provided by mother } \\
\text { (literacy) }\end{array}$ & $\begin{array}{l}\text { in progress; more input } \\
\text { (systematic instruction } \\
\text { of Japanese provided by } \\
\text { the mother) }\end{array}$ \\
\cline { 2 - 4 } & weekend Polish school & $\begin{array}{l}\text { weekend Polish } \\
\text { school: considered }\end{array}$ & $\begin{array}{l}\text { weekend Polish school: } \\
\text { failed }\end{array}$ \\
\hline
\end{tabular}

Table 2. Family Language Policy: 2015 vs. 2017.

Based on the longitudinal study conducted, it might be concluded that FLP appears to be a dynamic, evolving process, shaped by all family members and a range of sociocultural, economic and political factors. The results have revealed huge discrepancies between parents' language ideologies and their actual practices. Both parents are strongly convinced about the value of their heritage languages, as well as multilingualism in their child's socio-cognitive development, yet their actual language practices do in fact enhance the dominance of the majority language and assimilation with the host culture. This trend is to a large extent enforced by the child, who seems to be deeply integrated with the local community and perceives herself as "English".

The study has also provided evidence that the parents consider language to be a source of not only cultural but also social and economic capital, which is consistent with the findings of the study conducted by A. Berardi-Wilthsire (2018). The parents, especially the mother, believe that English-Japanese bilingualism might turn out to be a profitable asset for their daughter, offering a potential competitive advantage in the global job market. Moreover, officially certified foreign language proficiency is also seen as facilitating admission to the top higher education institutions in the UK that the parents are already considering for their daughter. These beliefs translate into concrete actions that involve, e.g. the provision of systematic Japanese language instruction to the child, aimed at preparation for the FL proficiency exam. The commitment undertaken demonstrates that the parents are thinking strategically about language management to ensure their daughter reaps as many benefits as possible of the language resources at her disposal. Yet, the decisive role in particular language choices is played by Maja herself, which again points to child agency in shaping FLP. 
The participation in the study has also had an educational-reflective dimension for the family members, especially the parents. First of all, their interest in bilingualism/multilingualism has become more informed. The father has read several academic publications on the issue and both parents have become familiar with some popular writings on it. Secondly, the family's language management and its verification have become more conscious and systematic. Finally, the parents have redefined the perception of success concerning their family's multilingual development, which has been deemed "partial" yet "satisfactory". In other words, the parents have stopped blaming themselves for their perceived "failure" in raising a trilingual child and accepted the status quo.

\section{References}

Berardi-Wiltshire, A. (2018), Parental ideologies and Family language Policies among Spanish-speaking migrants to New Zealand. In: "Journal of Iberian and Lain American Research" 23(3), 271-285.

Blackledge, A./ A. Pavlenko (2002), Introduction. In: "Multilingua - Journal of Cross-Cultural and Interlanguage Communication" 21, 121-140.

Bourdieu, P. (1991), Language and Symbolic Power. Cambridge.

Caldas, S./ S. Caron-Caldas (2000), The Influence of Family, School, and Community on Bilingual Preference: Results from a Louisiana/Quebec Case Study. In: "Journal of Applied Psycholinguistics" 21(3), 365-381.

Caldas, S./ S. Caron-Caldas (2002), A Sociolinguistic Analysis of the Language Preferences of Adolescent Bilinguals: Shifting Allegiances and Developing Identities. In: "Applied Linguistics" 23 (4), 490-514.

Canagarajah, A.S. (2008), Language Shift and the Family: Questions from the Sri Lankan Tamil Diaspora. In: "Journal of Sociolinguistics" 12 (2), 143-176.

Cooper, R.L. (1989), Language Planning and Social Change. Cambridge.

Curdt-Christiansen, X.L. (2009), Invisible and Visible Language Planning: Ideological Factors in the Family Language Policy of Chinese Immigrant Families in Quebec. In: "Language Policy" 8 (4), 351-375.

Curdt-Christiansen, X.L. (2013), Caregiver Responses to the Language Mixing of a Young Trilingual. In: "Multilingua-Journal of Cross-Cultural and Interlanguage Communication" 32(1), 1-32.

de Houwer, A. (2007), Parental Language Input Patterns and Children's Bilingual Use. In: "Applied Psycholinguistics" 28, 411-424.

Döpke, S. (1992), One Parent One Language: An Interactional Approach. Amsterdam.

Dörnyei, Z. (2007), Research Methods in Applied Linguistics: Quantitative, Qualitative and Mixed Methodologies. Oxford.

Fishman, J.A. (1991), Reversing Language Shift: Theoretical and Empirical Foundations of Assistance to Threatened Languages. Clevedon.

Fogle, L. (2012), Second Language Socialization and Learner Agency. Clevedon. 
Fogle, L./ K.A. King (2013), Child Agency and Language Policy in Transnational Families. In: "Issues in Applied Linguistics" 19 (1), 1-25.

Gafaranga, J. (2010), Medium Request: Talking Language Shift into Being. In: "Language in Society" 39 (2), 241-270.

Harding, E./ P. Riley (1986), The Bilingual Family: A Handbook for Parents. Cambridge.

Harris, J.R. (1995), Where Is the Child's Environment? A Group Socialization Theory of Development. In: "Psychological Review" 103 (3), 458-489.

Haugen, E. (1972), The ecology of language. Stanford.

Hoffmann, C. (1985), Language Acquisition in Two Trilingual Children. In: Journal of Multilingual and Multicultural Development 6, 479-495.

Hymes, D.H. (1974), Foundations in sociolinguistics: An ethnolinguistic approach. Philadelphia.

Hymes, D.H. (1967), Models of the interaction of language and social setting. In: "Journal of Social Issues" 23 (2), 8-38.

King, K.A./ L.W. Fogle (2006), Bilingual Parenting as Good Parenting: Parents' Perspectives on Family Language Policy for Additive Bilingualism. In: "International Journal of Bilingual Education and Bilingualism" 9 (6), 695-712.

King, K.A./ L. Fogle (2013), Family Language Policy and Bilingual Parenting. In: "Language Teaching" 46 (2), 172-194.

King, K.A./ L. Fogle/ A. Logan-Terry (2008), Family Language Policy. In: "Language and Linguistics Compass" 2, 1-16.

Laihonen, P. (2008), Language Ideologies in Interviews: A Conversation Analysis Approach. In: "Journal of Sociolinguistics" 12, 668-693.

Lankiewicz, H./ E. Wąsikiewicz-Firlej (in press), Developing Intercultural Sensitivity through Translation Activities: Beyond the Monolingual Premise in Foreign Language Education. In: "Neofilolog".

Lanza, E./ B.E. Svendsen (2007), Tell Me Who Your Friends Are and I Might Be Able to Tell You What Language(s) You Speak: Social Network Analysis, Multilingualism, and Identity. In: "International Journal of Bilingualism" 11, 275-300.

Lanza, E. (1992), Can Bilingual Two-year-olds Code-switch?. In: "Journal of Child Language" 19 (3), 633-658.

Lanza, E. (1997), Language Mixing in Infant Bilingualism: A Sociolinguistic Perspective. Oxford.

Lanza, E. (2007), Multilingualism in the Family. In: A. Peter/ W. Li (eds.), Handbook of multilingualism and multilingual communication. Berlin, 45-67.

Luykx, A. (2005), Children as Socializing Agents: Family Language Policy in Situations of Language Shift. In: J. Cohen/ K.T. McAlister/ J. MacSwan/ K. Rolstad (eds.), ISB4: Proceedings of the 4th international symposium on bilingualism. Somerville, 1407-1414.

Moin, V./ L. Schwartz/ M. Leikin (2013), Immigrant Parents' Lay Theories of Children's Preschool Bilingual Development and Family Language Ideologies. In: "International Multilingual Research Journal" 7, 99-118. 
Ochs, E./ B. Schieffelin (1984), Language Acquisition and Socialization: Three Developmental Stories. In: R. Shweder/ L.R. LeVine (eds.), Culture Theory: Essays on Mind, Self and Emotion. New York, 276-320.

Okita, T. (2002), Invisible Work: Bilingualism, Language Choice and Childrearing in Intermarried Families. Amsterdam.

Palviainen, A../ S. Boyd (2013), Unity in Discourse, Diversity in Practice. In: M. Schwartz/ A. Verschik (eds.), Successful Family Language Policy: Parents, Children and Educators in Interaction: Multilingual Education 7. Heidelberg, 223-248.

Schwartz, M. (2008), Exploring the Relationship between Family Language Policy and Heritage Language Knowledge among Second Generation Russian-Jewish Immigrants in Israel. In: "Journal of Multilingual and Multicultural Development" 29 (5), 400-418.

Schwartz, M. (2010), Family Language Policy: Core Issues of an Emerging Field. In: "Applied Linguistics Review" 1(1), 171-192.

Schwartz, M./ A. Verschik (2013), Achieving Success in Family Language Policy: Parents, Children and Educators in Interaction. In: M. Schwartz/ A. Verschik (eds.), Successful Family Language Policy: Parents, Children and Educators in Interaction: Multilingual Education 7. Heidelberg, 1-20.

Shohamy, E. (2006), Language Policy: Hidden Agendas and New Approaches. New York.

Spolsky, B. (2004), Language policy. Cambridge.

Spolsky, B. (2012), Family Language Policy - the Critical Domain. In: Journal of Multilingual and Multicultural Development" 33(1), 3-11.

Stake, R.E., (2005), Qualitative Case Studies. In: N.K. Denzin/ Y.S. Lincoln (eds.), The Sage Handbook of Qualitative Research (3rd ed.). Thousand Oaks, CA, 443-466.

Tannenbaum, M. (2003), The Multifaceted Aspects of Language Maintenance: A New Measure for Its Assessment in Immigrant Families. In: "International Journal of Bilingual Education and Bilingualism" 6 (5), 374-388.

Tuominen, A. (1999), Who Decides the Home Language? A Look at Multilingual Families. In: "International Journal of the Sociology of Language" 140, 59-76.

van Lier, L. (2005), Case Study. In: E. Hinkel (ed.), Handbook of Research in Second Language Learning, Mahwah, NJ, 195-208.

Volk, D./ M. Angelova (2007), Language Ideology and the Mediation of Language Choice in Peer Interactions in a Dual-language First Grade. In: "Journal of Language, Identity \& Education" 6, 177-199.

Wąsikiewicz-Firlej, E. (2016), Język i tożsamość w rodzinie transnarodowej: studium przypadku. In: „Neofilolog” 47 (2), 153-170.

Wittenbrink, B./ N. Schwarz (eds.), (2007), Implicit Measures of Attitudes. New York.

Wolfram, W./ N. Schilling-Estes (2006), American English: Dialects and Variation $\left(2^{\text {nd }}\right.$ ed. $)$. Oxford. 